\title{
Differences in the distribution of CD20, CD3, CD34 and CD45RO in nasal mucosa and polyps from patients with chronic rhinosinusitis
}

\author{
MIHAELA MITROI $^{1 *}$, DANA ALBULESCU $^{2 *}$, ALINA CAPITANESCU $^{1 *}$, ANCA OANA DOCEA $^{3}$, \\ GABRIELA MUSAT $^{4}$, GEORGE MITROI ${ }^{5}$, OVIDIU ZLATIAN ${ }^{6}$, ARISTIDIS TSATSAKIS $^{7}$, \\ GEORGE TZANAKAKIS $^{8}$, DEMETRIOS A. SPANDIDOS $^{9}$ and DANIELA CALINA ${ }^{10}$
}

\begin{abstract}
Departments of ${ }^{1}$ Otorhinolaryngology, ${ }^{2}$ Radiology, and ${ }^{3}$ Toxicology, University of Medicine and Pharmacy of Craiova, 200349 Craiova; ${ }^{4}$ Department of Otorhinolaryngology, University of Medicine and Pharmacy 'Carol Davila', 050474 Bucharest; Departments of ${ }^{5}$ Urology, and ${ }^{6}$ Microbiology, University of Medicine and Pharmacy of Craiova, 200349 Craiova, Romania;

${ }^{7}$ Laboratory of Toxicology, ${ }^{8}$ Laboratory of Anatomy-Histology-Embryology, and ${ }^{9}$ Laboratory of Clinical Virology, Medical School, University of Crete, 71003 Heraklion, Greece; ${ }^{10}$ Department of Clinical Pharmacy, University of Medicine and Pharmacy of Craiova, 200349 Craiova, Romania
\end{abstract}

Received December 20, 2018; Accepted February 1, 2019

DOI: $10.3892 / \mathrm{mmr} .2019 .9932$

\begin{abstract}
The present study focused on the assessment of the inflammatory infiltrate that characterizes nasal polyps in patients with chronic rhinosinusitis and nasal polyposis. Inflammatory cell type was determined using specific markers. This evaluation was made possible by determining the expression of the following markers: CD20, a marker of B lymphocytes [using activated T cells (ATC) armed with CD20 antibody]; CD3, a marker of T lymphocytes (using ATC armed with anti-CD3 antibody); CD45, the leukocyte common antigen (using ATC armed with anti-CD45 antibody; and CD34, for the microvasculature of the nasal polyp (using anti-CD34 antibody). The diagnosis of chronic rhinosinusitis with nasal polyps (CRSwNP) was made according to current EPOS guidelines based on patient history, clinical examination and nasal endoscopy. We examined surgically resected nasal polyps from 127 patients diagnosed with CRSwNP, who benefited from surgical procedures at the Department of Otorhinolaryngology of our institution. The polyps were analyzed at the Department
\end{abstract}

Correspondence to: Dr Anca Oana Docea, Department of Toxicology, University of Medicine and Pharmacy of Craiova, 2 Petru Rareș Street, 200349 Craiova, Romania

E-mail: ancadocea@gmail.com

Dr Daniela Calina, Department of Clinical Pharmacy, University of Medicine and Pharmacy of Craiova, 2 Petru Rareş Street, 200349 Craiova, Romania

E-mail: calinadaniela@gmail.com

*Contributed equally

Key words: chronic rhinosinusitis, nasal polyposis, CD20, CD3, CD45RO, CD34 of Pathology of our institution utilizing histopathological and immunohistochemical methods as follows: Firstly, the tissues were paraffin-impregnated, sectioned and stained with hematoxylin and eosin. We then examined the expression of CD3, CD20, CD34 and CD45RO by immunohistochemistry with soluble labeled streptavidin biotin (LSAB)/horseradish peroxidase (HRP) complexes. We observed the following histopathological changes: The structure of the epithelium was evidenced by collagenous subjacent stroma with mixed areas, sometimes associated with hyaline zones. In all types of polyps, we also observed a diffuse underlayer or periglandular lymphoplasmacytic in filtrate composed predominantly from T lymphocytes and eosinophils. The histopathological changes suggest the chronic inflammation of the sinus mucosa, which was diffusely distributed in allergic polyps and with nodular distribution in fibro-inflammatory polyps. The number of B lymphocytes was greater in the fibro-inflammatory polyps. On the whole, the findings of this study indicate that the inflammatory infiltrate in nasal polyps from patients with CRSwNP is mainly composed of $\mathrm{T}$ cells and eosinophils in all types of polyposis. In addition, a diffuse distribution of allergic polyps and the nodular distribution of fibro-inflammatory polyps, and the hyperplasia of the seromucous glands was observed. The determination of CD20, CD3, CD34 and CD45RO could be used to assess the inflammatory infiltrate of the nasal poplyps in these patients.

\section{Introduction}

One of the most frequent pathology in Otorhinolaryngology practice is chronic rhinosinusitis (CRS), which in the United States, affects $14 \%$ of the population, associated with an increasing incidence of allergic rhinitis. CRS has a considerable social and economic burden due mainly to frequent visits to primary care facilities, as well as to an increase in the use 
of pharmaceutical products (1). The quality of life index of patients CRS, measured by bodily pain and social functioning is significantly lower than that of patients with angina, congestive heart failure, chronic obstructive pulmonary disease or even back pain (2). Even if CRS is a highly prevalent disease, there is a paucity of accurate epidemiological data, as compared to available data on the diagnosis, microbiology and treatment of the condition (3).

CRS is a chronic inflammatory disease which affects the nasal cavities and paranasal sinuses; however, under this term are likewise grouped a heterogeneous group of diseases, which have different etiologies and pathological mechanisms (4). The CRS milieu can act as a reservoir of bacteria (5) that may cause other respiratory infections, such as laryngitis, tracheitis, bronchitis and pneumonia (6), as well as distant surgical site-like infections (7) and even invasive infections in rare cases (8). The diagnosis of CRS is usually clinical and straightforward and is based upon criteria established by the American Academy of Otorhinolaryngology: The presence of two or more significant symptoms (anterior or posterior rhinorrhea, nasal obstruction/congestion, hyposmia/anosmia and facial pain/pressure) which last for $>12$ weeks, confirmed by the results of nasal endoscopy and/or a CT scan (1).

There are two types of CRS: CRS with nasal polyps (CRSwNP) and CRS without nasal polyps (CRSsNP) (9). Different molecular mechanisms are involved in the formation of nasal polyps. The genetic alterations include the mutation and differential expression of the ras family of genes (10). Expression analyses have revealed the downregulation of wild-type B-Raf proto-oncogene serine/threonine kinase (BRAF) (11) and the increased expression of angiogenic markers, such as vascular endothelial growth factor A (VEGFA) or transforming growth factor $\beta 1$ (TGF- $\beta 1$ ) (12). Another mechanism for the formation of nasal polyps is infection with viruses, such as human herpes virus or human papillomavirus (13). A previous histological study demonstrated a significantly high proportion of tissue eosinophilia in CRS, most prominently in patients with CRSwNP (14).

B lymphocytes are a key constituent of the adaptive immune response and play important roles in various inflammatory disorders (15-18). Although the most well-known role of B lymphocytes is to produce antibodies that can contribute to disease pathogenesis, B cells can also act as antigen-presenting cells or regulatory cells by producing a large array of cytokines that influence the inflammatory response. Recently, it was demonstrated that the expression of TNF B cell-activating factor (BAFF) is greatly increased in the nasal polyps of patients with CRSwNP (16). Furthermore, several histopathological studies have demonstrated increased levels of immunoglobulins $\operatorname{IgG}, \operatorname{IgE}$ and $\operatorname{IgA}$ in the sinuses of patients with CRS (19-22).

As far as T cells are concerned, our understanding of their activity in the nasal mucosa is based on extrapolation, using cell cultures as a starting point, that can be obtained from brushed nasal epithelial cells $(23,24)$. There are also studies on biopsies from nasal polyps showing the role of cytokines, such as tumor necrosis factor- $\alpha$ (TNF- $\alpha$ ) (25) or other cytokines (26). Dendritic cells (DCs) serve as the primary antigen-presenting cells (APCs) in the process of the nasal immune response and consequently, they present antigens to naive T lymphocytes (27).
CD45 is a protein tyrosine phosphatase (PTP), that is expressed by hematopoietic cells, with the exception of platelets and mature erythrocytes. PTP is encoded by the PTPRC gene located on chromosome 1. Furthermore, CD45 plays important roles in T cell receptor (TCR) and B cell receptor (BCR) signal transduction. CD45 isoforms are specific to the activation and maturation state of the cells. There are 3 isoforms of CD45: B220 expressed on B lymphocytes, CD45 RA expressed on naive $\mathrm{T}$ lymphocytes and $\mathrm{CD} 45 \mathrm{RO}$ expressed on activated and memory $\mathrm{T}$ lymphocytes (28).

CD20 is considered a pan-antigen for B lymphocytes, expressed on mature B cells, but not on active plasmocytes (18). CD20 is a membrane non-glycosylated phosphoprotein of 33-37 kDa which contains three hydrophobic regions that are embedded in the cell membranes. Additional amino and carboxyl long ends are localized intracellularly with only a portion of the molecule exposed extracellularly. This antigen is involved in the modulation of B cells, proliferation and differentiation. The CD20 antigen is expressed early in the development of pre-B cells, supposedly even before the cytoplasmic expression of alpha chains whereas it is not detected in plasma cells. This antigen is not expressed by monocytes, erythrocytes and mesenchymal cells (29).

Major producers of interleukin (IL)-13 and IL-5 are the group 2 innate lymphoid cells (ILC2s) $(30,31)$. These cells are involved in the Th2 type inflammatory response and mediate among other processes, intestinal immunity to helminths, the hyperreactivity of the airways and asthmatic bronchial obstruction $(32,33)$.

The treatment of CRS is based on corticosteroids, antibiotics and endoscopic sinus surgery. However, the application of these treatments does not induce a significant change in the evolution of the disease, the need for surgery or in the prevention of recurrences (34-36). Clearly the pathogenesis of CRS and factors that promote mucosal inflammation requires a deeper understood in order to develop novel diagnostic and therapeutic tools or strategies.

On the basis of the above-mentioned aspects, the present study, which analyzes fragments of nasal polyps surgically resected from patients with CRSwNP, proposes the assessment of B lymphocytes [using activated T cells (ATC) armed with CD20 antibody] and T lymphocytes (using ATC armed with anti-CD3 antibody), the presence of $\mathrm{CD} 45^{+}$cells (the leukocyte common antigen) and the evaluation of vasculature of nasal polyp (CD34+ cells) to assess the inflammatory infiltrate of nasal polyps.

\section{Materials and methods}

Patients and samples. Fragments of the polyps removed from 127 patients with CRSwNP who underwent surgery at the Otorhinolaryngology Clinic of Clinical County Emergency Hospital of Craiova, Romania, between January and July, 2018 were histologically analyzed. We used the histologically normal areas of the extracted surgical piece as a control normal mucosa. The access of the database with patient demographic and clinical electronic records for the purpose of this study was approved by the Ethics Committee of Clinical County Emergency Hospital of Craiova, Romania. As we are a teaching hospital, all patients admitted to our hospital signed 
a written consent by which they agreed that their medical data could be used in scientific studies.

In order for patients to be included in this study, compliance to certain criteria was necessary, including the following: i) A symptomatology that lasted for $>12$ weeks, without complete resolution: Nasal obstruction, muco-purulent nasal discharge, hyposmia or anosmia, headaches with exacerbations secondary to bacterial infections. ii) Different changes in the region of the middle meatus, such as edema or polyps, observed upon the endoscopic examination of nasal cavities.

The biological material was surgically obtained, under general anesthesia, and analyzed at the Laboratory of Pathology, Emergency County Hospital, Craiova, Romania. The tissues were fixed in $10 \%$ buffered formalin, for $24 \mathrm{~h}$. For histopathological analysis, the sections were then embedded in paraffin and stained with hematoxylin and eosin (H\&E; Sanimed SA, Bucharest, Romania). Serial sections (3-4- $\mu$ m-thick) were cut from paraffin blocks (automated rotating microtome Leica RM2255), and placed on lamellas treated with poly-L-Lysine (Sigma-Aldrich, Munich, Germany) and allowed to dry at laboratory temperature for $12 \mathrm{~h}$. At room temperature, the slides were treated with Mayer hematoxylin for $3 \mathrm{~min}$, washed, differentiated for $10 \mathrm{sec}$ in alcohol-hydrochloric acid solution, washed again, stained with eosin solution for $15 \mathrm{sec}$, dehydrated in 3 baths of alcohol (60 degrees, 96 degrees and finally absolute alcohol) and clarified in 3 toluene baths. Finally the slides were mounted using Canada balm (Sigma-Aldrich).

Immunohistochemistry. For immunohistochemistry, the paraffin sections with the same thickness as mentioned above (3-4 $\mu \mathrm{m}$ ) were attached on to electrostatically treated slides, deparaffinized in xylene at $58^{\circ} \mathrm{C}$ for $1 \mathrm{~h}$, then 2 more times for $10 \mathrm{~min}$ at room temperature, fixed in cold acetone $\left(4^{\circ} \mathrm{C}\right)$ for $5 \mathrm{~min}$ and then let to air-dry at room temperature for $30 \mathrm{~min}$. Immunohistochemistry was carried out using soluble labeled streptavidin biotin (LSAB)/horseradish peroxidase (HRP) complexes. Streptavidin is an avidin tetrameric analog with a 60-kDa molecular weight, extracted from Streptomyces avidinii bacterium, able to bind easier to the molecules of biotin. The affinity of streptavidin for biotin is 10 -fold greater, which leads to an intense specific detection and amplification of antigen-antibody links. We used the Dako LSAB 2 System HRP kit (Universal DAKO Labeled Streptavidin Biotin 2 System Horseradish Peroxidase), as previously described (37). The sections were incubated in peroxidase blocking solution (hydrogen peroxide 3\%) for $10 \mathrm{~min}$ at room temperature and rinsed with phosphate-buffered saline (PBS). The slides were pre-treated in order to reveal the antigen by microwaves and were incubated in a wet room contact with primary antibody for about 1 hour at room temperature. goat anti-rabbit $\operatorname{IgG}(\mathrm{h}+\mathrm{l})$ secondary antibody (cat. no. 31820; Thermo Fisher Scientific, San Frascisco, CA, USA) was added and the slides were incubated at room temperature for $30 \mathrm{~min}$. After washing in clean water, the slides were incubated with streptavidin peroxidase at room temperature for $10 \mathrm{~min}$. The chromogen-substrate [3,3'-diaminobenzidine (DAB)] was added in a dark room and once the brown color appeared, the slides were submerged in water for stopping and then stained with hematoxylin for $3 \mathrm{~min}$. The slides were dehydrated through $95 \%$ ethanol for 2 min and
2 times in $100 \%$ ethanol for $3 \mathrm{~min}$. Finally, the sections were mounted in Canada balm (cat. no. C1795; Sigma-Aldrich).

In the immunohistochemical analysis, we used concentrated antibodies from Thermo Fisher Scientific as follows: CD20 mouse IgG monoclonal antibody (HI47), PE (cat. no. MHCD2004-4), CD3 mouse IgG monoclonal antibody (S4.1) (cat. no. Q10484), CD45 mouse IgG monoclonal antibody (HI30), pacific orange (cat. no. MHCD4530TR) and CD34 mouse IgG monoclonal antibody (BI-3C5) (cat. no. 07-3403). In order to obtain optimal dilution, the antibodies were weak in the PBS-azide solution.

The immunohistochemical staining visualized the investigated antigens using DAB chromogen, which caused a brown precipitate (cell nucleus was stained light blue by hematoxylin). Immunohistochemical staining was evaluated by a 4-grade system, according to the model established by the European Organization for Research and Treatment of Cancer-Gynaecological Cancer Cooperative Group in 1997 (38), as follows: Absent (-), weak intensity (+), moderate intensity (++) and strong immunostaining (+++). After immunostaining was carried out, we assessed the number of cells per 20X field by examining 20 fields for each slide. The results were expressed as cells/field.

Statistical analysis. All numerical data are expressed as the median (interquartile range). For sex data, we used the one-sample Z-test to determine whether the proportion of males differed significantly from $50 \%$ for each age group (in other words if there was a significant difference between the proportion of males and females). For count data we used $2 \times 2$ or $2 \times 3$ Chi-squared tests. To determine differences between multiple groups, we used the non-parametric Wilcoxon test, as some distribution data were skewed and we had a low number of hyperplastic polyps, followed by the post-hoc Mann-Whitney test with the Holm-Sidak adjustment for multiple comparisons. The statistical significance level was set at 0.05 .

\section{Results}

Demographic data. There were no significant differences in sex distribution among patients in the specific age groups with the exception of the 11-20-year age category, which exhibited a significantly higher precedence of males (male:female ratio, 2.07:1; Table I).

Histopathological changes. We classified the histopathological changes of the nasal polyps according to the Davidsson and Hellquist classification (39). We examined 127 nasal polyps that were classified as follows: Allergic polyps (with eosinophilic infiltrate), 69 cases (54.33\%); fibro inflammatory polyps, 47 cases $(37.01 \%)$; and hyperplastic polyps with marked hyperplasia of the seromucous glands, 11 cases $(8.67 \%)$. The allergic and fibro-inflammatory polyps were mostly ulcerated, whereas the hyperplastic polyps were mostly non-ulcerated (Table II).

We observed the following histopathological changes: The structure of the epithelium was evidenced by collagenous subjacent stroma with mixed areas, sometimes associated with hyaline zones. The pseudostratified columnar epithelium predominated in all types of polyps, but was more 
Table I. Age and sex distribution of patients with nasal polyposis.

\begin{tabular}{|c|c|c|c|c|c|}
\hline Age & Male & Female & Male:female ratio & Total, n (\%) & P-value \\
\hline $0-10$ years & 3 & 3 & $1.00: 1$ & $6(4.72)$ & 0.999 \\
\hline $11-20$ years & 31 & 15 & 2.07:1 & $46(36.22)$ & 0.018 \\
\hline $21-30$ years & 13 & 11 & $1.18: 1$ & $24(18.90)$ & 0.683 \\
\hline $31-40$ years & 12 & 5 & $2.40: 1$ & $17(13.38)$ & 0.089 \\
\hline $41-50$ years & 9 & 5 & $1.80: 1$ & $14(11.02)$ & 0.2849 \\
\hline $51-60$ years & 13 & 7 & $1.86: 1$ & $20(15.75)$ & 0.180 \\
\hline Total & 81 & 46 & $1.76: 1$ & 127 & $<0.001$ \\
\hline
\end{tabular}

The one-sample Z-test was used to determine whether the proportion of males differed significantly from $50 \%$.
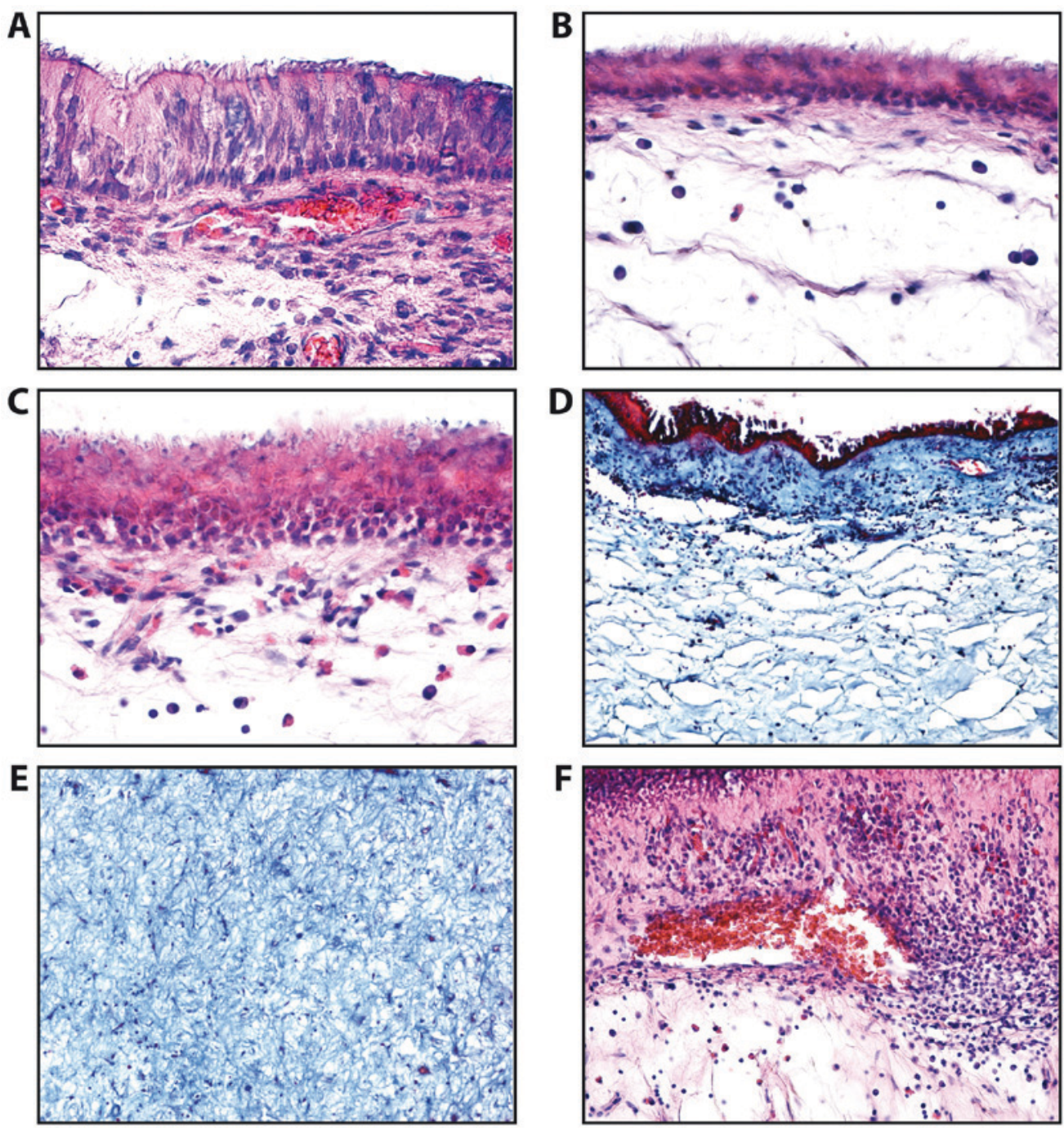

Figure 1. Epithelial types observed in the nasal mucosa and polyps of patients with chronic rhinosinusitis. (A) Normal epithelium (H\&E staining, $\mathrm{x} 200$ magnification). (B) Atrophic epithelium squamous metaplasia of epithelium (H\&E staining, x200 magnification). (C) Squamous metaplasia of the epithelium (H\&E staining, x200 magnification). (D) Lamina propria of nasal polyp (H\&E staining, x100 magnification). (E) Fibrous areas of lamina propria of nasal polyp (H\&E staining, x100 magnification). (F) Nasal polyp; areas with vascular congestion (H\&E staining, x100 magnification).

frequent in fibro-inflammatory polyps (91.48\%). In all types of polyps, we also observed a diffuse underlayer or periglandular lymphoplasmacytic infiltrate composed predominantly from $\mathrm{T}$ lymphocytes and eosinophils. The histopathological changes suggest the chronic inflammation of the sinus mucosa, diffusely distributed in allergic polyps and with nodular distribution in fibro-inflammatory polyps.

In this study, we identified normal epithelium composed of tall cells (Fig. 1A), atrophic epithelium (Fig. 1B), squamous metaplasia of the epithelium (Fig. 1C) with the chorion moder- 
ately infiltrated with lymphocytes, plasma cells and sometimes eosinophils. The lamina propria and stromal polyp appeared in many fibrous and spongy areas (Fig. 1D and E). Areas with vascular congestion and abundant inflammatory infiltrate were also detected (Fig. 1F). The basal membrane often appeared thickened.

Analysis of immunostaining. In allergic polyps, immunostaining for CD45RO revealed a diffuse localization of activated and memory $\mathrm{T}$ lymphocytes, which presented distinct immunostaining at the cell membrane (Fig. 2A). In fibro-inflammatory polyps, $\mathrm{CD} 45 \mathrm{RO}$ staining revealed numerous activated $\mathrm{T}$ lymphocytes with distinct immunostaining at the membrane level; however, we also observed an underlayer with mostly periglandular arrangement. In some cases, the infiltrate formed lymphoid follicles (Fig. 2B). The activated and memory $\mathrm{T}$ lymphocytes $\left(\mathrm{CD} 45 \mathrm{RO}^{+}\right)$were most abundant in allergic polyps followed by fibro-inflammatory polyps and hyperplastic polyps (Table III), the differences between the immunostaining level between the polyp types were all significant $(\mathrm{P}<0.05)$.

Anti-CD20 monoclonal antibody underlined a continuous mark for B lymphocytes at the membrane level. In all the polyps, the B lymphocytes were much less represented compared with the population of $\mathrm{T}$ lymphocytes, that were diffusely present in the polyp stroma (Fig. 3). We observed an increase in the numbers of B lymphocytes in the fibro-inflammatory polyps (Table III).

The Tlymphocytes $\left(\mathrm{CD}^{+}\right)$were barely present in the lamina propria of the mucosal polyp and in the deep stroma (Fig. 4). In the allergic polyps, CD3 immunostaining revealed that the $\mathrm{T}$ lymphocytes exhibited a diffuse distribution in the stroma of the analyzed polyps. In general, $\mathrm{T}$ lymphocytes were much more numerous in the fibro-inflammatory and hyperplastic polyps than in the allergic ones (Table III).

The microvasculature of all nasal polyps exhibited a non-homogeneous distribution, with the most intensely vascular areas being the areas of the lymphoid infiltration (CD34+) (Table III and Fig. 5).

\section{Discussion}

Although CRS is a common disease, commonly addressed by the healthcare facilities, the pathology of the disease is poorly understood and the therapeutic options are limited, which results in a significant loss of the quality of life of the affected patients and induces a substantial financial burden $(2,40)$. As regards the demographic data from the present study, there was no significant difference between the number of men and women with nasal polyps, as in other studies (41), although the majority of patients with nasal polyps were middle-aged, at around 40 years of age. In this study, most polyps were from patients aged 11-20 years, as many parents turned to the hospital otorhinolaryngology specialists for polypectomy. The higher male:female ratio in the 11-20 year old age group detected in this study is well in accordance with that of another study (42). In addition, Vento et al (43) identified a male:female ratio of 2.4:1 and Diamantopoulos et al (44) determined a male:female ratio of 3.3:1.

The majority of nasal polyps that were resected were of the allergic type (69 polyps), then of the fibro-inflammatory type 

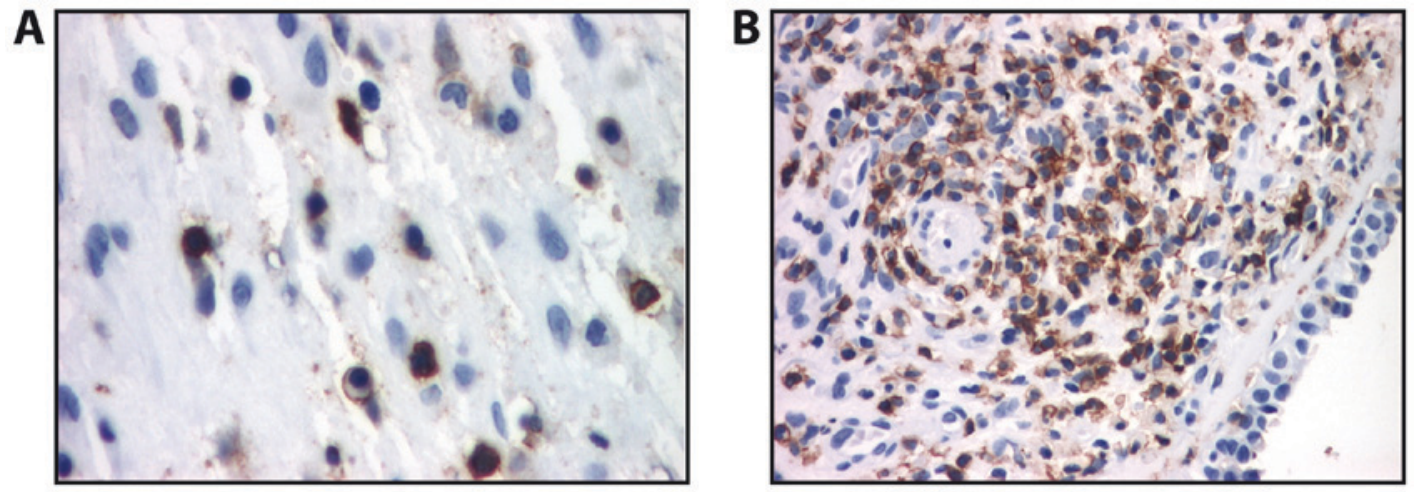

Figure 2. Immunohistochemistry of nasal polyps. (A) Allergic polyp (CD45RO immunostaining, x400 magnification). (B) Fibro-inflammatory polyp with tendency to the formation of lymphoid follicles (CD45RO immunostaining, x200 magnification).
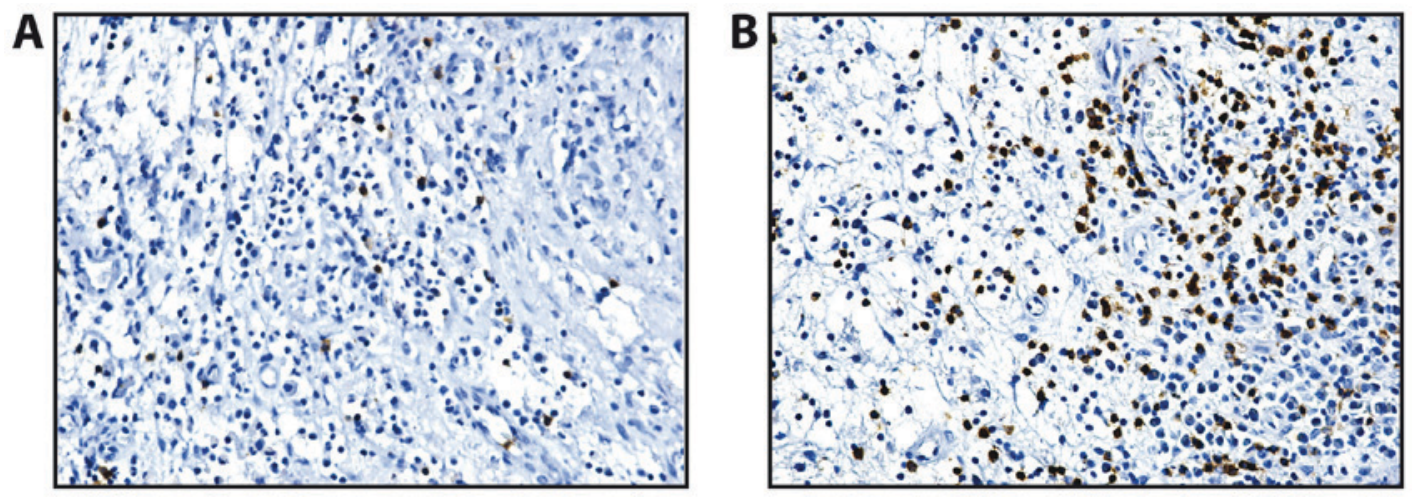

Figure 3. Immunohistochemistry of nasal polyps (CD20 immunostaining, x100 magnification). (A) Allergic polyp. (B) Fibro-inflammatory polyp.
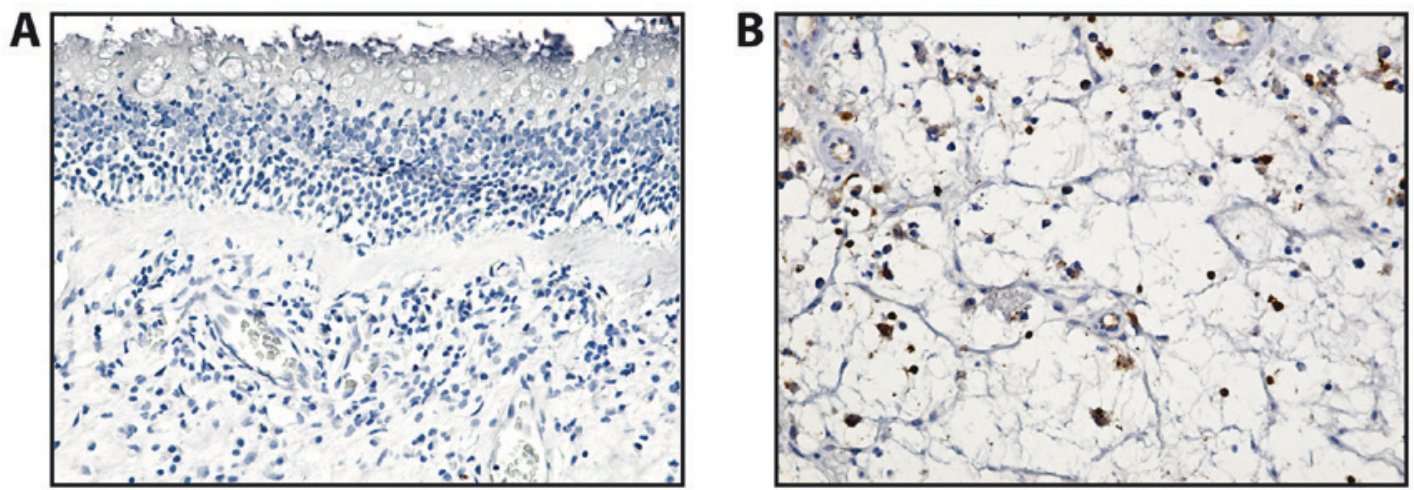

Figure 4. Immunohistochemistry of nasal polyps (CD3 immunostaining, 100X objective). (A) Allergic polyp - immunostaining in lamina propria of the mucosal polyp. (B) Fibroinflammatory polyp - immunostaining in deep stroma of the mucosal polyp.

secondary to infection or other causes (47 polyps). In addition, 11 polyps were classified as hyperplastic.

The histopathological findings of this study revealed that ulceration was present in a high percentage of the allergic and fibro-inflammatory polyps. A previous study on African, Chinese and Caucasian populations demonstrated that $10-20 \%$ of hyperplastic polyps were ulcerated as opposed to $75 \%$ of fibro-inflammatory and allergic polyps (45). The study by Lathi et al that included 112 Indian patients found that $62.5 \%$ from the polyps were of the allergic type and $25 \%$ of the fibro-inflammatory type, that is similar with our percentages of
$54.33,37.01$ and $8.67 \%$, respectively (46). The high percentage of ulceration may be due to trauma or mechanical pressure of growing polyps inside nasal cavities.

In a separate study by Tripathi and Ranjan (47) performed on 119 polyp biopsies in the pathology laboratory, it was shown that $79.1 \%$ of the polyps had pseudostratified ciliated columnar epithelium, $18.8 \%$ had squamous epithelium and $2.1 \%$ transitional epithelium. These findings were confirmed in this study, which identified a pseudostratified ciliated columnar epithelium in $84.06 \%$ of the allergic polyps, whereas the squamous epithelium and transitional epithelium were identified in 11.59 and 
Table III. Distribution of eosinophils, $\mathrm{T}$ lymphocytes $\left(\mathrm{CD} 3^{+}\right)$, B lymphocytes $\left(\mathrm{CD} 20^{+}\right), \mathrm{CD} 34^{+}$cells and $\mathrm{CD} 34^{+}$vessels in different types of polyps.

\begin{tabular}{|c|c|c|c|c|c|c|c|}
\hline & $\begin{array}{l}\text { Allergic } \\
\text { polyps } \\
(\mathrm{n}=69)\end{array}$ & $\begin{array}{c}\text { Fibro- } \\
\text { inflammatory } \\
\text { polyps } \\
(\mathrm{n}=47)\end{array}$ & $\begin{array}{l}\text { Hyperplastic } \\
\text { polyps } \\
(\mathrm{n}=11)\end{array}$ & $\begin{array}{l}\text { Group } \\
\text { difference }\end{array}$ & $\begin{array}{c}\text { Allergic } \\
\text { vs. fibro- } \\
\text { inflammatory }\end{array}$ & $\begin{array}{l}\text { Allergic vs. } \\
\text { hyperplastic }\end{array}$ & $\begin{array}{c}\text { Fibro- } \\
\text { inflammatory } \\
\text { vs. hyperplastic }\end{array}$ \\
\hline Parameter & $\begin{array}{l}\text { Median } \\
(\mathrm{IQR})\end{array}$ & $\begin{array}{l}\text { Median } \\
(\mathrm{IQR})\end{array}$ & $\begin{array}{c}\text { Median } \\
(\mathrm{IQR})\end{array}$ & P-value & P-value & P-value & P-value \\
\hline $\begin{array}{l}\text { Eosinophils } \\
\text { (cells/20X field) }\end{array}$ & $\begin{array}{c}128.3 \\
(81.5-181.6)\end{array}$ & $\begin{array}{c}3.4 \\
(0.64-8.2)\end{array}$ & $\begin{array}{c}0 \\
(0-0.4)\end{array}$ & $<0.001$ & $<0.001$ & $<0.001$ & 0.007 \\
\hline $\begin{array}{l}\text { T lymphocytes }\left(\mathrm{CD}^{+}\right) \\
\text {(cells/20X field) }\end{array}$ & $\begin{array}{c}28.9 \\
(28.5-71.9)\end{array}$ & $\begin{array}{c}61.7 \\
(35.2-112.8)\end{array}$ & $\begin{array}{c}55.7 \\
(38.1-65.4)\end{array}$ & $<0.001$ & $<0.001$ & $<0.001$ & 0.580 \\
\hline $\begin{array}{l}\text { Activated and memory } \\
\left(\mathrm{CD}^{2} 5 \mathrm{RO}^{+}\right) \\
\mathrm{T} \text { lymphocytes } \\
\text { (cells/20X field) }\end{array}$ & $\begin{array}{c}19.4 \\
(14.3-22.7)\end{array}$ & $\begin{array}{c}14.3 \\
(12.1-15.7)\end{array}$ & $\begin{array}{c}12.5 \\
(10.5-15.4)\end{array}$ & $<0.001$ & $<0.001$ & $<0.001$ & 0.009 \\
\hline $\begin{array}{l}\text { B lymphocytes }\left(\mathrm{CD} 20^{+}\right) \\
\text {(cells/20X field) }\end{array}$ & $\begin{array}{c}12.9 \\
(10.5-23.4)\end{array}$ & $\begin{array}{c}33.4 \\
(14.7-38.2)\end{array}$ & $\begin{array}{c}22.3 \\
(12.5-33.1)\end{array}$ & $<0.001$ & $<0.001$ & $<0.001$ & 0.054 \\
\hline $\mathrm{CD} 4^{+}$cells/20X field & $\begin{array}{c}14.3 \\
(12.1-17.8)\end{array}$ & $\begin{array}{c}42.7 \\
(36.5-48.9)\end{array}$ & $\begin{array}{c}28.2 \\
(24.1-30.5)\end{array}$ & $<0.001$ & $<0.001$ & $<0.001$ & $<0.001$ \\
\hline $\mathrm{CD} 4^{+}$vessels $/ 0.5 \mathrm{~mm}^{2}$ & $\begin{array}{c}60.3 \\
(55.8-62.4)\end{array}$ & $\begin{array}{c}190.3 \\
(170.7-211.9)\end{array}$ & $\begin{array}{c}127.1 \\
(117.1-132.5)\end{array}$ & $<0.001$ & $<0.001$ & $<0.001$ & $<0.001$ \\
\hline
\end{tabular}

We used the non-parametric Wilcoxon test, followed by the post-hoc Mann-Whitney test with Holm-Sidak adjustment for multiple comparisons. hpf, high-power field.

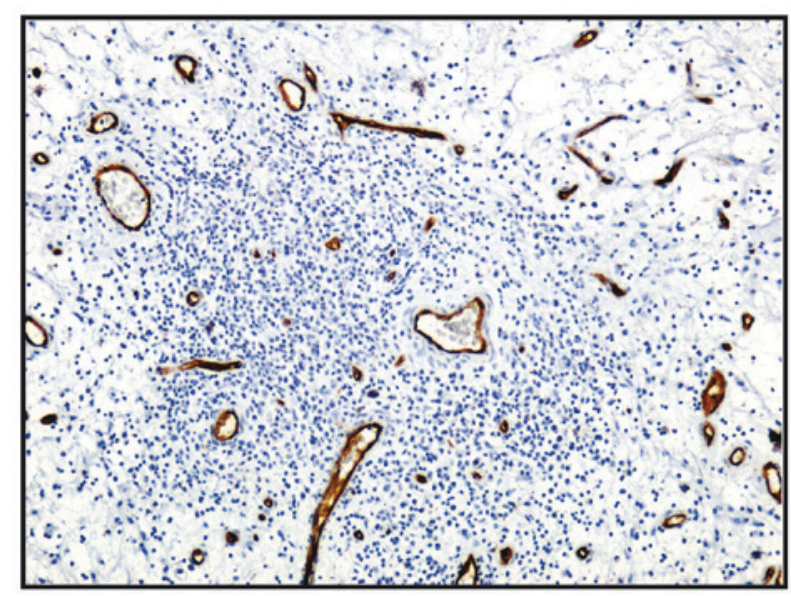

Figure 5. Vasculature of nasal polyps; CD34 immunostaining, x100 magnification.

$4.35 \%$ of the cases, respectively in these polyp types. Moreover, in all types of polyps, significant differences between the types of epithelium were detected in our study in hyperplastic polyps $(\mathrm{P}=0.025)$ and highly significant differences in allergic and fibroinflammatory polyps $(\mathrm{P}<0.001)$.

The most important factors in the pathogenesis of CRS are identified as both the chronic activation of a variety of inflammatory cells such as B cells, a key component of the adaptive immune response, as well as the defects in innate immunity $(19,48)$. A number of studies have focused on B and T lymphocyte expression, as well as on the inflammatory infiltrate in patients with CRS with or without nasal polyposis. Thus, it has been noted that the number of $\mathrm{CD}^{+}$cells, $\mathrm{CD} 20^{+}$cells and plasma cells in nasal polyps are significantly higher compared to those in the middle turbinates (49). The inflammatory infiltrate and cell proliferation are associated with the presentation of nasal polyps (50). It has been observed that in patients with nasal polyposis associated with cystic fibrosis, there is an increase in the number and activation state of $\mathrm{T}$ lymphocytes and an increase in the number of plasma cells. Furthermore, in nasal polyps, increased levels of eosinophils, eosinophil cationic protein (ECP) and eotaxin compared with CRS and controls were determined. Patients with CRS present with Th1 polarization and an increase in IFN- $\gamma$ and TGF- $\beta$ levels, with nasal polyps showing Th2 polarization/high IL-5 and IgE (51).

In the study by Hulse et al (52), there was no significant difference between the median number of CD20+ cells per high-power field (hpf) in CRS tissues as compared with the controls. However, we must take into account the known difficulty of measuring protein expression by immunohistochemistry. A much better method for the quantitative characterization of B cell populations is flow cytometry. The utilization of this method has demonstrated a significantly higher number of $\mathrm{CD} 9^{+} \mathrm{B}$ cells in CRSwNP compared with healthy control subjects or CRSsNP patients (53).

The polyps present higher levels of BAFF that correlates with an increased expression of CD20 (54), leading to the 
conclusion that B lymphocytes found in polyp tissue favor a microenvironment for activation, proliferation and differentiation (55). Furthermore, decreased apoptosis in polyps from aspirin-sensitive patients and the eosinophilic infiltration has been linked to an increased expression of CD45RO ${ }^{+}$ activated/memory cells and to the clinical features of the rhinosinusitis has been demonstrated (56). The number of CD45-positive cells is higher in patients with CRSwNP compared to those with CRSsNP $(\mathrm{P}<0.01)$. The number of $\mathrm{CD} 45^{+}$cells in nasal polyps has been shown to increase $>2$-fold the total number of cells (57).

In this study, in all types of polyps, continuous marking for B lymphocytes at the membrane level was detected. The underlayer or periglandular lymphoplasmacytic infiltrate was composed predominantly from $\mathrm{T}$ lymphocytes and eosinophils with diffuse disposition at the stroma level, as revealed by CD45 and CD3 immunostaining.

The distribution of the microvasculature had a nonhomogeneous distribution in nasal polyps as the most intensely vascular area were lymphoid infiltration areas $\left(\mathrm{CD} 34^{+}\right)$. The histopathological changes suggest the chronic inflammation of sinus mucosa, diffusely distributed in allergic polyps and with nodular distribution in fibro-inflammatory polyps. The number of B lymphocytes was slightly greater in the fibro-inflammatory polyps.

In conclusion, the findings of the present study demonstrate that the inflammatory infiltrate in nasal polyps is composed mainly from $\mathrm{T}$ cells and eosinophils in all types of polyposis. We observed a diffuse distribution in the allergic polyps and nodular distribution in the fibro-inflammatory polyps, and also a hyperplasia of the seromucous glands. The number of B lymphocytes was slightly increased in the fibro-inflammatory polyps. Further studies are required in order to fully understand the pathology of CRS and to find novel therapeutic options.

\section{Acknowledgements}

Not applicable.

\section{Funding}

No funding was received.

\section{Availability of data and materials}

All data generated or analyzed during the current study are included in this published article or are available from the corresponding author upon reasonable request.

\section{Authors' contributions}

All the authors were involved in conceiving and designing the study. MM, AC and GMu contributed to sample collection. MM, DA, AC and GMi collected the data. OZ, GMi performed the statistical analysis. DC, AOD, GT and OZ drafted and wrote the manuscript. DC, AOD, DAS, GT and AMT gave advice on the experimental design, interpreted the results and critically revised the manuscript. All authors have read and approved the final version of the manuscript.

\section{Ethics approval and consent to participate}

The access of the database for the purpose of this study was approved by the Ethics Committee of Clinical County Emergency Hospital of Craiova, Romania. As we are a teaching hospital, all patients admitted to our hospital signed a written consent by which they agree that their medical data can be used in scientific studies.

\section{Patient consent for publication}

Not applicable.

\section{Competing interests}

DAS is the Editor-in-Chief for the journal, but had no personal involvement in the reviewing process, or any influence in terms of adjudicating on the final decision, for this article.

\section{References}

1. Jankowski R, Rumeau C, Gallet P and Nguyen DT: Nasal polyposis (or chronic olfactory rhinitis). Eur Ann Otorhinolaryngol Head Neck Dis 135: 191-196, 2018.

2. Khairuddin NK, Salina H, Gendeh BS, Wan Hamizan AK and Lund VJ: Quality of life and recurrence of disease in patients with eosinophilic and non-eosinophilic 1 chronic rhinosinusitis with nasal polyposis. Med J Malaysia 73: 1-6, 2018.

3. Fokkens WJ, Lund VJ, Mullol J, Bachert C, Alobid I, Baroody F, Cohen N, Cervin A, Douglas R, Gevaert P, et al: EPOS 2012: European position paper on rhinosinusitis and nasal polyps 2012. A summary for otorhinolaryngologists. Rhinology 50: 1-12, 2012.

4. Stevens WW, Schleimer RP, Chandra RK and Peters AT: Biology of nasal polyposis. J Allergy Clin Immunol 133: 1503, 1503.e1-4, 2014.

5. Ungureanu A, Zlatian O, Mitroi G, Drocaş A, Ţîrcă T, Călina D, Dehelean C, Docea AO, Izotov BN, Rakitskii VN, et al: Staphylococcus aureus colonisation in patients from a primary regional hospital. Mol Med Rep 16: 8771-8780, 2017.

6. Calina D, Rosu L, Rosu AF, Ianosi G, Ianosi S, Zlatian O, Mitrut R Docea AO, Rogoveanu O and Mitrut P: Etiological diagnosis and pharmacotherapeutic management of parapneumonic pleurisy. Farmacia 64: 946-952, 2016.

7. Călina D, Docea AO, Rosu L, Zlatian O, Rosu AF, Anghelina F, Rogoveanu O, Arsene AL, Nicolae AC, Drăgoi CM, et al: Antimicrobial resistance development following surgical site infections. Mol Med Rep 15: 681-688, 2017.

8. Zlatian O, Balasoiu AT, Balasoiu M, Cristea O, Docea AO, Mitrut R, Spandidos DA, Tsatsakis AM, Bancescu G and Calina D: Antimicrobial resistance in bacterial pathogens among hospitalised patients with severe invasive infections. Exp Ther Med 16: 4499-4510, 2018.

9. Dennis SK, Lam K and Luong A: A Review of classification schemes for chronic rhinosinusitis with nasal polyposis endotypes. Laryngoscope Investig Otolaryngol 1: 130-134, 2016.

10. Zaravinos A, Bizakis J, Soufla G, Sourvinos G and Spandidos DA: Mutations and differential expression of the ras family genes in human nasal polyposis. Int J Oncol 31: 1051-1059, 2007.

11. Zaravinos A, Bizakis J and Spandidos DA: RKIP and BRAF aberrations in human nasal polyps and the adjacent turbinate mucosae. Cancer Lett 264: 288-298, 2008.

12. Zaravinos A, Soufla G, Bizakis J and Spandidos DA: Expression analysis of VEGFA, FGF2, TGFbeta1, EGF and IGF1 in human nasal polyposis. Oncol Rep 19: 385-391, 2008.

13. Zaravinos A, Bizakis J and Spandidos DA: Prevalence of human papilloma virus and human herpes virus types 1-7 in human nasal polyposis. J Med Virol 81: 1613-1619, 2009.

14. Gitomer SA, Fountain CR, Kingdom TT, Getz AE, Sillau SH, Katial RK and Ramakrishnan VR: Clinical examination of tissue eosinophilia in patients with chronic rhinosinusitis and nasal polyposis. Otolaryngol Head Neck Surg 155: 173-178, 2016.

15. Koennecke M,Pries R and Wollenberg B: Regulatory dysfunctions in nasal polyposis. HNO 66: 290-295, 2018 (In German). 
16. Ickrath P, Kleinsasser N, Ding X, Ginzkey C, Beyersdorf N, Kerkau T, Hagen R and Hackenberg S: Impact and modulations of peripheral and edaphic B cell subpopulations in chronic rhinosinusitis with nasal polyposis. Clin Exp Otorhinolaryngol 11: 133-140, 2018.

17. Wongratanacheewin S: Significant role of cytokines and signaling pathway in rheumatoid arthritis, nasal polyposis and human airway smooth muscle cells. Asian Pac J Allergy Immunol 31: 1-2, 2013.

18. Chin D and Harvey RJ: Nasal polyposis: An inflammatory condition requiring effective anti-inflammatory treatment. Curr Opin Otolaryngol Head Neck Surg 21: 23-30, 2013.

19. Tan BK, Peters AT, Schleimer RP and Hulse KE: Pathogenic and protective roles of $\mathrm{B}$ cells and antibodies in patients with chronic rhinosinusitis. J Allergy Clin Immunol 141: 1553-1560, 2018

20. Chen JB, James LK, Davies AM, Wu YB, Rimmer J, Lund VJ, Chen JH, McDonnell JM, Chan YC, Hutchins GH, et al: Antibodies and superantibodies in patients with chronic rhinosinusitis with nasal polyps. J Allergy Clin Immunol 139: 1195-1204 e1111, 2017.

21. Pratt E, Collins AM, Sewell WA and Harvey RJ: Antigen selection in $\mathrm{IgE}$ antibodies from individuals with chronic rhinosinusitis with nasal polyps. Am J Rhinol Allergy 24: 416-421, 2010.

22. Gonçalves C, Pinaffi JV, Carvalho JF, Pinna FR, Constantino GT Voegels RL, Bueno C, Bonfá E and Viana VS: Antineutrophil cytoplasmic antibodies in chronic rhinosinusitis may be a marker of undisclosed vasculitis. Am J Rhinol 21: 691-694, 2007.

23. Brewington JJ, Filbrandt ET, LaRosa FJ III, Moncivaiz JD, Ostmann AJ, Strecker LM and Clancy JP: Brushed nasal epithelial cells are a surrogate for bronchial epithelial CFTR studies. JCI Insight 3: 3, 2018.

24. Bridges MA: Culture of airway epithelial cells collected by a nasal brushing technique. In Vitro Cell Dev Biol Anim 33: 82-83, 1997.

25. Bradding P, Mediwake R, Feather IH, Madden J, Church MK, Holgate ST and Howarth PH: TNF alpha is localized to nasal mucosal mast cells and is released in acute allergic rhinitis. Clin Exp Allergy 25: 406-415, 1995.

26. Boita M, Bucca C, Riva G, Heffler E and Rolla G: Release of type 2 cytokines by epithelial cells of nasal polyps. J Immuno Res 2016: 2643297, 2016.

27. Jacobi HH, Liang Y, Tingsgaard PK, Larsen PL, Poulsen LK, Skov PS, Haak-Frendscho M, Niles AL and Johansson O: Dendritic mast cells in the human nasal mucosa. Lab Invest 78: 1179-1184, 1998.

28. Rheinländer A, Schraven B and Bommhardt U: CD45 in human physiology and clinical medicine. Immunol Lett 196: 22-32, 2018.

29. Casan JM, Wong J, Northcott MJ and Opat S: Anti-CD20 monoclonal antibodies: Reviewing a revolution. Hum Vaccin Immunother: Aug 10, 2018 (Epub ahead of print). doi: 10.1080/2 1645515.2018.1508624

30. No authors listed: Abstracts of The International Symposium of Recent Update in Rhinosinusitis and Nasal Polyposis. Med J Malaysia 71 (Suppl 2): 1-35, 2016.

31. Moro K, Yamada T, Tanabe M, Takeuchi T, Ikawa T, Kawamoto H, Furusawa J, Ohtani M, Fujii H and Koyasu S: Innate production of $\mathrm{T}(\mathrm{H}) 2$ cytokines by adipose tissue-associated c-Kit(+)Sca-1(+) lymphoid cells. Nature 463: 540-544, 2010.

32. Halim TY, Krauss RH, Sun AC and Takei F: Lung natural helper cells are a critical source of Th2 cell-type cytokines in protease allergen-induced airway inflammation. Immunity 36: 451-463, 2012.

33. Yasuda K, Muto T, Kawagoe T, Matsumoto M, Sasaki Y, Matsushita K, Taki Y, Futatsugi-Yumikura S, Tsutsui H, Ishii KJ, et al: Contribution of IL-33-activated type II innate lymphoid cells to pulmonary eosinophilia in intestinal nematode-infected mice. Proc Natl Acad Sci USA 109: 3451-3456, 2012.

34. Kang SH, Dalcin PT, Piltcher OB and Migliavacca RO: Chronic rhinosinusitis and nasal polyposis in cystic fibrosis: Update on diagnosis and treatment. J Bras Pneumol 41: 65-76, 2015.

35. Bachert C, Zhang L and Gevaert P: Current and future treatment options for adult chronic rhinosinusitis: Focus on nasal polyposis. J Allergy Clin Immunol 136: 1431-1440, 2015.

36. Csomor P, Sziklai I and Karosi T: Effects of intranasal steroid treatment on the presence of biofilms in non-allergic patients with chronic rhinosinusitis with nasal polyposis. Eur Arch Otorhinolaryngol 271: 1057-1065, 2014.

37. Mitroi M, Căpitănescu A, Georgescu CV, Mogoantă CA, Popescu C, Georgescu M, Mitroi G and Ioniţă E: Expression pattern of CK7 and CK20 in nasal polyps, at patients with chronic rhinosinusitis with nasal polyposis. Rom J Morphol Embryol 52 (Suppl 3): 1051-1057, 2011.
38. van Diest PJ, van Dam P, Henzen-Logmans SC, Berns E, van der Burg ME, Green J and Vergote I; European Organization for Research and Treatment of Cancer-Gynaecological Cancer Cooperative Group: A scoring system for immunohistochemical staining: Consensus report of the task force for basic research of the EORTC-GCCG. J Clin Pathol 50: 801-804, 1997.

39. Davidsson A and Hellquist HB: The so-called 'allergic' nasal polyp. ORL J Otorhinolaryngol Relat Spec 55: 30-35, 1993.

40. Aboud SK, Husain S and Gendeh BS: Evaluation on quality of life in patients with nasal polyposis managed with optimal medical therapy. Allergy Rhinol (Providence) 5: 2-8, 2014.

41. Cortesina G, Cardarelli L, Riontino E, Majore L, Ragona R and Bussi M: Multi-center study of recurrent nasal sinus polyposis: Prognostic factors and possibility of prophylaxis. Acta Otorhinolaryngol Ital 19: 315-324, 1999 (In Italian).

42. Settipane GA: Epidemiology of nasal polyps. Allergy Asthma Proc 17: 231-236, 1996.

43. Vento SI, Wolff CH, Salven PJ, Hytönen ML, Ertama LO and Malmberg CH: Vascular permeability factor/vascular endothelial growth factor in nasal polyps. Acta Otolaryngol Suppl 543: $170-174,2000$.

44. Diamantopoulos II, Jones NS and Lowe J: All nasal polyps need histological examination: An audit-based appraisal of clinical practice. J Laryngol Otol 114: 755-759, 2000.

45. Lacroix JS, Zheng CG, Goytom SH, Landis B, Szalay-Quinodoz I and Malis DD: Histological comparison of nasal polyposis in black African, Chinese and Caucasian patients. Rhinology 40: 118-121, 2002.

46. Lathi A, Syed MM, Kalakoti P, Qutub D and Kishve SP: Clinico-pathological profile of sinonasal masses: A study from a tertiary care hospital of India. Acta Otorhinolaryngol Ital 31: 372-377, 2011.

47. Tripathi P and Ranjan R: A comparative study of histopathology of different types of nasal polyps: Allergic, inflammatory and neoplastic. Ann Int Med Dent Res 3: 41-45, 2017.

48. Takeda K, Sakakibara S, Yamashita K, Motooka D, Nakamura S, El Hussien MA, Katayama J, Maeda Y, Nakata M, Hamada S, et al: Allergic conversion of protective mucosal immunity against nasal bacteria in patients with chronic rhinosinusitis with nasal polyposis. J Allergy Clin Immunol: Jul 25, 2018 (Epub ahead of print). doi: 10.1016/j.jaci.2018.07.006.

49. Wang X, Guo J, Zhang H, Tao G, Han D, Zhu X, Fan E and Li Y: Roles of CD43, CD20 and local IgE in the pathogenesis of nasal polyps. Zhonghua Er Bi Yan Hou Ke Za Zhi 36: 333-334, 2001 (In Chinese).

50. Wu X, Wang LF and Zang YH: Expression of CD68 CD45RO $\mathrm{CD} 20$ and proliferating cell nuclear antigen in nasal polyps Zhonghua Er Bi Yan Hou Ke Za Zhi 38: 187-190, 2003 (In Chinese).

51. Sobol SE, Christodoulopoulos P, Manoukian JJ, Hauber HP, Frenkiel S, Desrosiers M, Fukakusa M, Schloss MD and Hamid Q: Cytokine profile of chronic sinusitis in patients with cystic fibrosis. Arch Otolaryngol Head Neck Surg 128: 1295-1298, 2002.

52. Hulse KE, Norton JE, Suh L, Zhong Q, Mahdavinia M, Simon P, Kern RC, Conley DB, Chandra RK, Tan BK, et al: Chronic rhinosinusitis with nasal polyps is characterized by B-cell inflammation and EBV-induced protein 2 expression. J Allergy Clin Immunol 131: 1075-83, 1083.e1-7, 2013.

53. Min JY, Hulse KE and Tan BK: B-cells and antibody-mediated pathogenesis in chronic rhinosinusitis with nasal polyps. Adv Otorhinolaryngol 79: 48-57, 2016.

54. Yoon YH, Jin J, Kwon KR, Kim SH, Rha KS and Kim YM: The role of B cell Activating Factor (BAFF) expression on pathogenesis of nasal polyp in chronic rhinosinusitis with nasal polyposis. Rhinology 52: 390-396, 2014

55. Hulse KE: Immune mechanisms of chronic rhinosinusitis. Curr Allergy Asthma Rep 16: 1, 2016.

56. Chen D, Chen L and Xiao L: The progress study of tumor suppressor gene and apoptosis gene in nasal polyps. Lin Chung Er Bi Yan Hou Tou Jing Wai Ke Za Zhi 29: 2099-2102, 2015 (In Chinese)

57. Kowalski ML, Grzegorczyk J, Pawliczak R, Kornatowski T, Wagrowska-Danilewicz M and Danilewicz M: Decreased apoptosis and distinct profile of infiltrating cells in the nasal polyps of patients with aspirin hypersensitivity. Allergy 57: 493-500, 2002

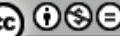

This work is licensed under a Creative Commons Attribution-NonCommercial-NoDerivatives 4.0 International (CC BY-NC-ND 4.0) License. 